\title{
All you can eat: The functional response of the cold-water coral Desmophyllum dianthus feeding on krill and copepods
}

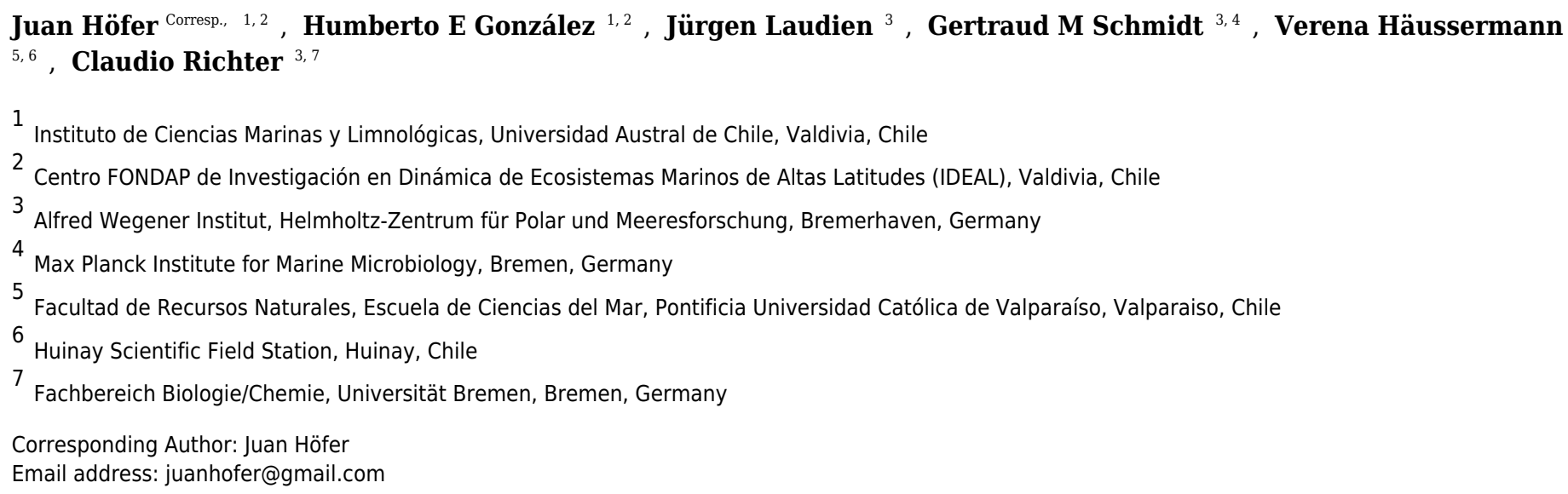

The feeding behavior of the cosmopolitan cold-water coral (CWC) Desmophyllum dianthus (Cnidaria: Scleractinia) is still poorly known. Its usual deep distribution restricts direct observations, and manipulative experiments are so far limited to prey that do not occur in CWC natural habitat. During a series of replicated incubations, we assessed the functional response of this coral feeding on a medium sized copepod (Calanoides patagoniensis) and a large euphausiid (Euphausia vallentini). Corals showed a Type I functional response, where feeding rate increased linearly with prey abundance, as predicted for a tentaculate passive suspension feeder. No significant differences in feeding were found between prey items, and corals were able to attain a maximum feeding rate of $10.99 \mathrm{mg} \mathrm{Ch}^{-1}$, which represents an ingestion of the $11.4 \%$ of the coral carbon biomass per hour. These findings suggest that $D$. dianthus is a generalist zooplankton predator capable of exploiting dense aggregations of zooplankton over a wide prey size-range. 


\section{All you can eat: The functional response of the cold-water coral}

\section{Desmophyllum dianthus feeding on krill and copepods}

3 Juan Höfer ${ }^{1,2}$, Humberto E. González ${ }^{1,2}$, Jürgen Laudien ${ }^{3}$, Gertraud M. Schmidt ${ }^{3,4}$, Verena

4 Häussermann ${ }^{5.6}$, Claudio Richter ${ }^{3.7}$

$5 \quad{ }^{1}$ Instituto de Ciencias Marinas y Limnológicas, Universidad Austral de Chile, Valdivia, Chile.

$6 \quad{ }^{2}$ Centro FONDAP de Investigación en Dinámica de Ecosistemas Marinos de Altas Latitudes

7 (IDEAL), Valdivia, Chile.

$8 \quad{ }^{3}$ Alfred Wegener Institut, Helmholtz-Zentrum für Polar und Meeresforschung, Bremerhaven,

9 Germany.

$10 \quad{ }^{4}$ Max Planck Institute for Marine Microbiology, Bremen, Germany.

$11{ }^{5}$ Facultad de Recursos Naturales, Escuela de Ciencias del Mar, Pontificia Universidad Católica

12 de Valparaíso, Valparaíso, Chile.

$13 \quad{ }^{6}$ Huinay Scientific Field Station, Huinay, Chile.

$14{ }^{7}$ Fachbereich Biologie/Chemie, Universität Bremen, Bremen, Germany.

15 Corresponding author;

16 Juan Höfer ${ }^{1,2}$

17 Email address: juanhofer@gmail.com 


\section{Abstract}

19 The feeding behavior of the cosmopolitan cold-water coral (CWC) Desmophyllum dianthus

20 (Cnidaria: Scleractinia) is still poorly known. Its usual deep distribution restricts direct

21 observations, and manipulative experiments are so far limited to prey that do not occur in CWC

22 natural habitat. During a series of replicated incubations, we assessed the functional response of

23 this coral feeding on a medium sized copepod (Calanoides patagoniensis) and a large euphausiid

24 (Euphausia vallentini). Corals showed a Type I functional response, where feeding rate increased

25 linearly with prey abundance, as predicted for a tentaculate passive suspension feeder. No

26 significant differences in feeding were found between prey items, and corals were able to attain a

27 maximum feeding rate of $10.99 \mathrm{mg} \mathrm{C} \mathrm{h}^{-1}$, which represents an ingestion of the $11.4 \%$ of the coral

28 carbon biomass per hour. These findings suggest that $D$. dianthus is a generalist zooplankton

29 predator capable of exploiting dense aggregations of zooplankton over a wide prey size-range. 


\section{Introduction}

32

In recent years, cold-water corals $(\mathrm{CWC})$ have received increasing attention from the scientific community as they were considered particularly vulnerable to global warming and ocean acidification (e.g. Doney et al., 2009; Maier et al., 2012; Jantzen et al., 2013a; Jantzen et al., 2013b; Lebrato et al., 2016). Although there are recent findings on how CWC may response to global change (e.g. Maier et al., 2012; Maier et al., 2013; Jantzen et al., 2013b; McCulloch et al., 2012a; McCulloch et al., 2012b; Findlay et al., 2014; Gori et al., 2016), there are still several uncertainties about their adaptive capacity. Part of them are due to the paucity of basic knowledge of the biology of CWC species, particularly in terms of growth, life cycle and feeding. For example, several CWCs seem able to up-regulate the $\mathrm{pH}$ of their internal calcifying fluid in order to cope with lower seawater $\mathrm{pH}$ (McCulloch et al., 2012a). However, the capacity to withstand unfavourable conditions likely depends on the nutrition level and the overall fitness of the corals (Guinotte et al., 2006; Jantzen et al., 2013a).

Desmophyllum dianthus (Esper, 1794) is a cosmopolitan CWC species (Cairns 1982; Cairns, Försterra \& Häussermann, 2005), that forms solitary polyps of up to $40 \mathrm{~cm}$ in height and $6.3 \mathrm{~cm}$ in diameter (Försterra \& Häussermann, 2003), and usually lives beyond the reach of divers between 35 and $2460 \mathrm{~m}$ depth (Cairns, 1995). In the northern hemisphere, it is often found in deep-water coral communities (Freiwald et al., 2004; Roberts et al., 2009) associated with Desmophyllum pertusum (Linnaeus, 1758) and Madrepora oculata Linnaeus, 1758 (Reveillaud et al., 2008; Heindel et al., 2010). In the southern hemisphere it constitutes the main CWC species in shallow coral banks off New Zealand and Chile (Squires, 1965; Cairns \& Stanley, 1982). However, the geographical distribution of $D$. dianthus may probably shrink in the near 
53 future due to physiological stress caused by ocean acidification and especially global warming

54 (Gori et al., 2016).

55 In the Comau Fjord (northern Patagonia, Chile; $\left.42^{\circ} 22.767 \mathrm{~S} 72^{\circ} 25.534 \mathrm{~W}\right)$ D. dianthus is

56 abundant (Försterra \& Häussermann, 2003; Jantzen et al., 2013a, b, Filinger \& Richter, 2013)

57 and locally dominates the benthic hard-bottom community (Försterra \& Häussermann, 2003;

58 Cairns, Försterra \& Häussermann, 2005). Here, the coral banks attain abundances of up to 1500

59 coral individuals per square meter (Cairns, Försterra \& Häussermann, 2005) and single

60 individuals have been found as shallow as $7 \mathrm{~m}$ (Försterra et al., 2005). A surface layer of

61 brackish water limits the upper coral distribution around $12 \mathrm{~m}$ depth (Försterra \& Häussermann,

62 2003; Cairns, Försterra \& Häussermann, 2005), while in the deep basin of the fjord the reduction

63 of its abundance seems to be related to higher metabolic costs due to lower oxygen concentration

64 combined with lower $\mathrm{pH}$ (Fillinger \& Richter, 2013). This shallow upper distribution in the

65 Comau Fjord represents a unique opportunity to collect $D$. dianthus for manipulative

66 experiments by scientific SCUBA diving.

67 In the past, the role of zooplankton in the CWC diet has been questioned due to the low

68 abundance of zooplankton in deep CWC habitats (Kiriakoulakis et al., 2005) and an insufficient

69 number of nematocysts to properly capture zooplankton (Lasker, 1981). However, recent

70 findings suggest that zooplankton may play an important role in the diet of D. dianthus (Carlier

71 et al., 2009; Mayr et al., 2011) being a major energy source for this CWC species (Naumann et

72 al., 2011). The few direct estimates of Desmophyllum feeding rates available are based on

73 laboratory experiments with non-naturally occurring prey, i.e. Artemia salina (Linnaeus, 1758)

74 (Tsounis et al., 2010), thus, the feeding behavior of this CWC on natural zooplankton is virtually 75 unexplored. 
76 The functional response examines predator-prey interactions that have direct implications for

77 population dynamics of both prey and predator (Holling, 1965; Murdoch, 1977), and constitutes

78 a key concept in trophic ecology (Holling, 1959; Holling, 1966), as it describes a species

79 capability to exploit resources for survival, growth and recruitment, which in the case of corals

80 also affects their mortality risk due to environmental stress (Anthony et al., 2009). The main goal

81 of this study was to examine the natural feeding behaviour of the CWC $D$. dianthus. In the

82 Mediterranean Sea, stable isotopes and observations suggest that copepods and euphausids may

83 be important prey items for Desmophyllum (Carlier et al., 2009; Tsounis et al., 2010). Our own

84 observations show that this seems to be the case also for D. dianthus in the Comau Fjord. We

85 therefore quantified the functional response of Patagonian D. dianthus feeding on two

86 corresponding natural zooplankters: Calanoides patagoniensis Brady, 1883, a medium sized

87 copepod, and Euphausia vallentini Stebbing, 1900, a large euphausiid. Comparison between the

88 functional response on each prey allow us to attain a first and comprehensive view of $D$.

89 dianthus natural feeding behavior. 
90 Material \& methods

91 Desmophyllum dianthus sampling

92 Desmophyllum dianthus was collected by scientific SCUBA divers in the Comau Fjord

93 (Northern Patagonia, Chile; see details in Försterra et al., 2005; Fillinger \& Richter, 2013) during

94 September and December 2016 and May 2017 (i.e. spring, summer and fall season). The

95 collection of corals was approved by the sub-secretariat of fisheries and farming within the

96 Chilean Ministry of Economy, Development \& Tourism (file number: 1760). In each season

97 circa twenty specimens of similar size $(\approx 3-4 \mathrm{~cm}$ long, $\approx 1.5-2 \mathrm{~cm}$ diameter $)$ were individually

98 chiseled off highly populated rocks near $42^{\circ} 14.935 \mathrm{~S}-72^{\circ} 30.880 \mathrm{~W}$ at $18-20 \mathrm{~m}$ depth. Corals

99 with no polyp tissue on their basis were selected to avoid infestations by endolithic or boring

100 sponges (Försterra et al., 2005; Jantzen et al., 2013b). Immediately after their collection, corals

101 were placed in a plastic container filled with their ambient seawater for transportation. This

102 prevented corals from suffering an osmotic shock when divers ascended through the shallow

103 brackish surface layer present within this fjord (Schwabe et al., 2006). Corals were immediately

104 transported to Huinay Scientific Field Station (HSFS), where they were placed in flow-through

105 aquaria constantly supplied with unfiltered fjord water from $24 \mathrm{~m}$ water depth to resemble their

106 natural conditions. Parts of the skeletons not covered with tissue were cut underwater with a

107 diamond blade equipped rotary tool (DREMEL Europe, Breda, Netherlands) before removing all

108 epibionts (e.g. microbial mats, tube-dwelling polychaetes, bryozoans) and gluing the corals to

109 polyethylene screws (Super Flex Glue Gel, UHU GmbH \& Co KG, Bühl, Germany). Corals

110 were allowed to acclimatize for at least $48 \mathrm{~h}$ before the incubation experiments started. During

111 this period, corals were regularly checked and only healthy corals with extended tentacles during 
112 night hours were used for the experiments. Then, the functional response of corals feeding on

113 krill and copepods was assessed (see details below and in Table 1).

114 Zooplankton sampling

115 Zooplankton samples were collected in front of HSFS during sunset and the first night hours.

116 Several vertical hauls from $100-150 \mathrm{~m}$ depth to the surface were made using a bongo net

117 (mouth of $40 \mathrm{~cm}$ diameter) equipped with a non-filtering cod end to reduce zooplankton stress

118 during sampling. For sampling medium-sized zooplankton (i.e. C. patagoniensis) the bongo net

119 was equipped with a $200 \mu \mathrm{m}$ mesh size, whereas $500 \mu \mathrm{m}$ mesh size was used for larger

120 zooplankton (i.e. E. vallentini). Immediately after sampling, the zooplankton was placed in a

121 cooler filled with unfiltered seawater from $24 \mathrm{~m}$ depth and transported to HSFS. Here, healthy

122 individuals of the target species were identified and selected under a stereomicroscope. Selected

123 individuals of $C$. patagonenis and E. vallentini were then placed in $500 \mathrm{~mL}$ Schott bottles (Schott

124 AG, Mainz, Germany) filled with $790 \mathrm{~mL}$ of seawater filtered through a $20 \mu \mathrm{m}$ sieve to remove

125 all zooplankters. Bottles containing zooplankton were then placed in a dark room for two or three

126 hours inside tanks with a constant flow of seawater from $24 \mathrm{~m}$ depth, maintaining zooplankton at

127 their environmental temperature while reducing their stress. All bottles were checked

128 immediately before performing functional response incubations and bottles containing unhealthy

129 zooplankton (i.e. non swimming) were discarded (see Table 1).

130 Functional response incubations

131 Normally, eight or nine specimens of $D$. dianthus (see Table 1) were placed upside down, similar

132 to their natural orientation, inside bottles containing healthy zooplankton (Fig. 1A), then moved

133 from HSFS laboratory to HSFS jetty and deployed hanging from the jetty at $\approx 8 \mathrm{~m}$ depth. This 
134 experimental set up simulates in situ conditions of temperature and light. On different days (i.e.

135 one for each prey type), corals experienced increasing zooplankton concentrations from 1.26 to

13611.39 euphausiids $\mathrm{L}^{-1}$ and from 2.53 to 50.63 copepods $\mathrm{L}^{-1}$ (see incubation details in Table 1).

137 Incubations started around midnight and lasted three hours to avoid oxygen consumptions larger

138 than $10 \%$, which might alter coral feeding behavior during the experiments (Table 1). Initial and

139 final oxygen concentrations were measured using a Hach HQ40D multiparameter probe. We

140 checked if the tentacles of the corals were extended at the beginning and end of the incubations

141 in order to discard any coral without totally extended tentacles, although no coral was discarded

142 due to this reason. Back at the laboratory of HSFS, corals were returned to the acclimatization

143 tanks. The remaining zooplankton (i.e. not captured by corals) was collected from the incubation

144 bottles using a $20 \mu \mathrm{m}$ sieve and then counted under a stereomicroscope. Zooplankton and corals

145 were subsequently frozen at $-20{ }^{\circ} \mathrm{C}$ and transported to the laboratory, where corals and

146 zooplankton were retrieved and dried in an oven at $58{ }^{\circ} \mathrm{C}$ for $48 \mathrm{~h}$. Euphausiids and copepods

147 were ground to a fine powder with a mortar and pestle, while corals were previously

148 decarbonated by immersion in liquid $\mathrm{HCl}(10 \%)$ at room temperature following the procedure

149 also used for Desmophyllum samples by Carlier et al. (2009). For elemental analysis, one coral

150 (D. dianthus), one euphausiid (E. vallentini), and 20 copepods (C. patagoniensis) were pooled

151 together, placed on pre-combusted glass fiber filters and assayed for carbon biomass content

152 (Table 1). Samples were weighed into tin cups $(3.3 \times 5 \mathrm{~mm})$, combusted at $900^{\circ} \mathrm{C}$, and analyzed

153 in a continuous flow isotope ratio mass spectrometer (Flash EA200 IRMS Delta Series, Thermo

154 Scientific, Germany).

155

$\underline{\text { Data analysis }}$ 
156 Statistical analyses were performed using the program R version 3.1.0 (R Core Team, 2012).

157 First of all, we analyzed if there were significant differences in the functional responses for each

158 prey among different seasons. An ANCOVA analysis was performed using the aov function

159 from the package stats to check if the slopes for each prey and season were significantly

160 different. Since the slopes for E. vallentini $(n=25, F=0.002$, $p$-value $=0.97)$ and $C$.

161 patagoniensis $(n=23, F=1.911, p$-value $=0.18)$ were not significantly different among seasons,

162 all data for each prey were pooled together for subsequent analysis.

163 Holling's (1959) functional response describes three different types (i.e. I, II and III) of

164 relationship between predator feeding rate and the abundance of its prey. In short, Type I

165 consists of a linear increase in the feeding rate with higher prey abundances, whereas Type II

166 depicts a feeding rate that increases with a decelerating rate with higher prey abundances until

167 the feeding rate reaches an asymptote (i.e. maximum feeding rate) that represents the saturation

168 of the predator and directly depends on the prey handling time. Type III is similar to Type II,

169 predator saturation with high prey abundances, but, with low prey abundances the increase in

170 feeding rate is closer to an exponential fit than a linear one. This is the consequence of the

171 predator learning time, i.e. the improvement in the attack and handling efficiency of the predator

172 feeding on that particular prey (see details in Holling, 1959).

173 Second-order logistic regressions were used to test which type of functional response was

174 exhibited by D. dianthus preying on C. patagoniensis and E. vallentini (see details in Trexler,

175 McCulloch \& Travis, 1988; Juliano 2001; Alexander et al., 2012). The effect of prey abundance

176 (i.e. food availability) on the proportion (parts per unit) of prey ingested by corals was explored

177 using the function glm from the stats package. Type I responses present non-significant linear

178 terms (Buckel \& Stoner 2000); whereas Type II has a significantly negative first-order term and 
179 Type III responses show a significantly positive first-order term, followed by a significantly

180 negative second-order term (Juliano 2001).

181 According to functional response Type I, ingestion rate increases linearly with prey abundance.

182 Model selection was used to test which kind of fit, linear or logarithmical, better explained the

183 relationship between coral ingestion rate and prey abundance. Model selection was performed

184 using second order Akaike Information Criteria (AICc). Functions lm (package stats) and aictab

185 (package AICcmodavg) were used for linear regressions and model selection, respectively. $C$.

186 patagoniensis and E. vallentini represent two different prey types due to their differences, e.g. in

187 size, swimming ability and feeding behavior. To examine if $D$. dianthus displayed different

188 feeding responses related to the prey type, the relationship between coral daily ration (\% of coral

189 carbon biomass ingested $\left.\mathrm{d}^{-1}\right)$ and prey biomass ( $\left.\mathrm{mg} \mathrm{C} \mathrm{L}^{-1}\right)$ was compared for each prey item. If

190 the prey type does not affect the response of $D$. dianthus, the linear regressions for $C$.

191 patagoniensis and E. vallentini should present similar slopes. The similarity of the slopes for $C$.

192 patagoniensis and $E$. vallentini was tested by an ANCOVA performed using the aov function

193 from the package stats. 


\section{Results}

195 Krill and copepods were actively swimming inside the incubation bottles at the end of each

196 experiment, while corals had their tentacles fully extended (Fig. 1B). Oxygen consumption

197 during all incubations was always lower than the $10 \%$ of the initial oxygen concentration (Table

198 1). All these evidences support the reliability of the results obtained during the incubations.

199 Functional response type

200 The proportion of prey (parts per unit) ingested by D. dianthus showed no pattern over a wide

201 range of prey abundances for C. patagoniensis and E. vallentini (Fig. 2). The second-order

202 logistic regressions for C. patagoniensis and E. vallentini (Fig. 2) did not present any significant

203 term (Table 2) pointing out that $D$. dianthus displayed a functional response Type I when feeding

204 on both prey. Corals actually feeding ate a mean $21.99 \%$ and $18.22 \%$ of copepods and

205 euphausiids, respectively (Fig. 2), with only a marginally significant difference between the

206 percentage of krill and copepods eaten (Kruskal-Wallis, $\chi^{2}=2.88$, $p$-value $=0.09$ ). The

207 proportion of prey eaten was approximately constant and did not depend on the number of prey

208 offered (Fig. 2), which means that coral ingestion rate would increase linearly with prey

209 abundance (Fig. 3).

210

211 Effect of prey abundance on Desmophyllum dianthus ingestion rate

212 Coral ingestion rate showed a good linear fitting with the abundance of prey (Fig. 3) agreeing

213 with the results expected for a functional response Type I (non-significant terms in Table 2).

214 Model selection indicates that the linear fitting model is the most probable one for both prey

215 items, explaining the $84 \%$ and $64 \%$ of the variance for C. patagoniensis and E. vallentini,

216 respectively (Table 3). 
218 Effects of prey type on the daily ration of Desmophyllum dianthus

219 The daily ration of $D$. dianthus feeding on $C$. patagoniensis and E. vallentini ranged from 0 to

$2208.19 \%$ and from 0 to $274.37 \%$ of coral carbon biomass $\mathrm{d}^{-1}$, respectively (Fig. 4). Coral daily

221 ration presented a similar response to the amount of carbon biomass offered despite of the

222 different prey types supplied, i.e. C. patagoniensis and E. vallentini (Fig. 4). According to

223 ANCOVA results the slopes displayed by $D$. dianthus feeding on both prey items did not differ

224 significantly $(F=0.002$, $p$-value $=0.9685)$, which means that $D$. dianthus feeds similarly

225 regardless of the prey type.

226 


\section{Discussion}

228 The CWC $D$. dianthus was able to efficiently prey on medium and large sized zooplankton, even

229 when corals faced prey abundances much higher than natural ones. To the best of our

230 knowledge, this is the first direct assessment of $D$. dianthus feeding on naturally co-occurring

231 zooplankton. Desmophyllum dianthus displayed a functional response Type I, which implies that

232 coral ingestion rate increases linearly with prey abundance. This response is typical for

233 suspension feeders in general (Jeschke, Kopp \& Tollrian, 2004) and corals in particular

234 (Anthony, 1999), which passively extend their crown of nematocyst-laden tentacles and

235 minimize handling by effectively paralyzing their prey, even at high densities. Desmophyllum

236 dianthus exhibited this response, i.e. functional response Type I, when feeding on a medium

237 sized copepod (C. patagoniensis) and a large euphausiid (E. vallentini). Besides, the daily ration

238 of corals increased similarly with the carbon biomass offered to corals regardless of the prey

239 species, suggesting that $D$. dianthus is potentially able to feed on a wide variety of zooplankton 240 prey.

241 Desmophyllum dianthus functional response feeding on zooplankton

242 The proportion of prey ingested by $D$. dianthus did not show any clear pattern with prey

243 abundance (Fig. 2 and Table 2), indicating a functional response Type I when corals feed on $C$.

244 patagoniensis and E. vallentini (Fig. 3). Functional response Type I implies that prey handling

245 time is so brief that it has a negligible effect on the coral food uptake, which leads to the high

246 ingestion rates display by more effective predators (Haddaway et al., 2012). Desmophyllum

247 dianthus is able to instantly paralyze even large krill (pers. obs.), explaining its non-saturation

248 state when facing very high abundances of krill. 
249 Previous studies using stable isotopes suggested that D. dianthus may feed mainly on

250 zooplankton instead of directly assimilate particulate organic matter, even presenting a slightly

251 higher trophic level than planktivorous fishes (Carlier et al., 2009; Mayr et al., 2011). Laboratory

252 studies also showed that Desmophyllum was able to capture Artemia (Tsounis et al., 2010),

253 which sustained coral respiration, growth and organic matter release (Naumann et al., 2011).

254 However, to this point, evidence of $D$. dianthus feeding effectively on naturally occurring 255 zooplankton was lacking.

256 Effect of prey abundance and prey type on Desmophyllum dianthus feeding

257 The ingestion rate of corals feeding on C. patagoniensis and E. vallentini increased linearly with

258 prey abundance (Fig. 3). During incubations corals experienced prey abundances (2.53 - 50.63

259 copepods $\mathrm{L}^{-1}$ and 1.26 - 11.39 euphausiids $\mathrm{L}^{-1}$ ) that were two to five orders of magnitude higher

260 than the natural abundances registered for copepods $\left(0.19\right.$ copepods $\left.\mathrm{L}^{-1}\right)$ and euphausiids $(0.0004$

261 euphausiids L ${ }^{-1}$ ) within the Comau Fjord (Sánchez, González \& Iriarte, 2011). Despite these very

262 large abundances, the feeding of $D$. dianthus displayed no saturation, suggesting that $D$. dianthus

263 is able to feed effectively on dense zooplankton aggregations swimming near corals. Here, we

264 recorded a maximum capture rate of 7.67 prey polyp ${ }^{-1} \mathrm{~h}^{-1}$ during C. patagoniensis incubations,

265 agreeing with previous records (8.48 prey polyp $\left.{ }^{-1} \mathrm{~h}^{-1}\right)$ of Desmophyllum feeding on Artemia

266 under optimal current conditions (Tsounis et al., 2010), which supports our findings that $D$.

267 dianthus was effectively feeding under very high prey abundances. Previous studies have shown

268 that zooplankton aggregations increase coral feeding (Genin et al., 2005) and zooplankton

269 swarms are common in fjord boundaries (Hirche, Laudien \& Buchholz, 2016) such as the steep

270 slopes surrounding the inner part of the Comau Fjord (Filinger \& Richter, 2013). Therefore, 
271 being able to feed properly on moving zooplankton swarms might be an adaptive strategy for

272 CWC living in a patchy and zooplankton scarce environment (Kiriakoulakis et al., 2005).

273 Desmophyllum dianthus daily ration showed the same relationship with the carbon biomass

274 offered regardless of the prey type, i.e. slopes showed no significant difference in Fig. 4

275 (ANCOVA, $F=0.002$, $p$-value $=0.9685$ ). Additionally, Desmophyllum is able to effectively

276 capture microzooplankton like nauplii (Tsounis et al., 2010), giving further support to $D$.

277 dianthus as a skilled generalist zooplankton predator. Desmophyllum dianthus was able to

278 capture a slightly higher percentage of copepods $(21.99 \%)$ than krill $(18.22 \%)$, which is

279 surprising since copepods are known to display an actual escape response to avoid predators (e.g.

280 Strickler \& Bal, 1973; Yen et al., 1992). Copepods escape from predators when they detect the

281 hydromechanical disturbances caused by them (Kerfoot, 1978; Haury, Kenyon \& Brooks, 1980).

282 The magnitude of this signal (i.e. velocity difference between predator and the environment)

283 determines the efficiency of predator detection and therefore copepod and nauplii escape success

284 against filter feeders, swimming and ambush predators (Viitasalo et al., 1998; Kiørboe, Saiz \&

285 Visser, 1999; Green et al., 2003; Titelman \& Kiørboe, 2003). However, CWC (including D.

286 dianthus) passively extend their tentacles to feed, which probably makes them virtually

287 undetectable for copepods and nauplii since the passively extended tentacles are very difficult to

288 distinguish from the surrounding waters using hydromechanical cues. The feeding strategy of $D$.

289 dianthus enables its ability to effectively capture copepods and nauplii, acting as a 'ghost

290 predator'.

291 General insights into Desmophyllum dianthus feeding ecology 
292 CWC were expected to not feed on zooplankton due to its paucity in the waters surrounding

293 them (Kiriakoulakis et al., 2005). However, stable isotopes (Duineveld et al., 2004; Carlier et al.,

294 2009; Mayr et al., 2011), laboratory experiments (Tsounis et al., 2010; Naumann et al., 2011)

295 and the present findings suggest that zooplankton is a major food source for CWC, including $D$.

296 dianthus. Zooplankton behavior promotes the formation of dense aggregations or swarms (Folt

$297 \&$ Burns, 1999; and references therein). Although these swarms may be spatially and temporally

298 scattered for corals, our results suggest that $D$. dianthus is able to prey effectively on dense

299 zooplankton aggregations such as krill swarms performing diel vertical migration. Euphausia

300 vallentini plays a major role in the pelagic food webs of the Chilean fjord region (González et al.,

$3012009 ; 2010 ; 2011 ; 2016)$, where E. vallentini migrates from $200 \mathrm{~m}$ depth to surface waters

302 (Hamame \& Antezana, 2010), representing an optimal feeding opportunity for D. dianthus

303 according to our findings. These dense vertical migrating swarms of E. vallentini within the

304 Comau Fjord might be fueling the high growth rates registered there $\left(2.2-10 \mathrm{~mm} \mathrm{yr}^{-1}\right.$, Jantzen

305 et al., 2013b) compared to other areas $\left(0.5-2.2 \mathrm{~mm} \mathrm{yr}^{-1}\right.$, Adkins et al., 2004). Besides, this extra

306 food supply may help D. dianthus to cope with the low pH (McCulloch et al., 2012a) that part of

307 its population experiences within the Comau Fjord (Jantzen et al., 2013a; Fillinger \& Richter,

308 2013).

309 CWC, such as D. dianthus, live in cooler waters than their tropical relatives, which implies less

310 energy losses due to metabolic costs. Although zooplankton may be available only during short

311 pulses, $D$. dianthus is able to seize these dense aggregations to feed actively as it is shown by the

312 present and previous findings (Tsounis et al., 2010). These short 'feeding windows' may be

313 enough for $D$. dianthus to avoid starvation and grow, while, between these 'feeding windows'

314 corals might exploit particulate (detritus, nano- and microplankton) and/or dissolved organic 
315 matter as it has been recorded for other corals (Orejas et al., 2001; Orejas, Gili \& Arntz, 2003;

316 Ribes, Coma \& Rossi, 2003; Tsounis et al., 2006). 


\section{Conclusions}

318 The ingestion rate of $D$. dianthus increased linearly with prey abundance (i.e. functional response

319 Type I) even when corals experienced prey abundances that were much higher than the natural 320 ones. This implies that $D$. dianthus is a capable zooplankton predator that seems to be adapted to 321 exploit dense zooplankton aggregations when they pass by. Finally, D. dianthus feeding response 322 showed no differences when preying upon a medium sized copepod or a large euphausiid, which 323 evidences, along with previous studies, that this CWC is able to effectively feed on a wide 324 variety of zooplankton prey.

325 


\section{Acknowledgments}

327 We are very grateful to the staff of Huinay Scientific Field Station, especially G. Försterra, for

328 their logistical support. F. Beaujot, A. Thomasberger and M. Schiønning assisted collecting

329 corals, while P. Martis and N. García-Herrera helped during incubations. This is a contribution of

330 the IDEAL research center and publication number 160 with contribution from Huinay Scientific

331 Field Station. N. García-Herrera kindly provided the pictures for Figure 1. Useful comments

332 from the editor and two reviewers helped us to improve the manuscript. 


\section{References}

Adkins JF, Henderson GM, Wanga SL, O'Shea S, Mokadembet F. 2004. Growth rates of the deep-sea scleractinia Desmophyllum cristagalli and Enallopsammia rostrata. Earth and Planetary Science Letters 227: 481-490. doi:10.1016/J.EPSL.2004.08.022

Alexander ME, Dick JTA, O'Connor NE, Haddaway NR, Farnsworth KD. 2012. Functional responses of the intertidal amphipod Echinogammarus marinus: effects of prey supply, model selection and habitat complexity. Marine Ecology Progress Series 468:191-202.

Anthony KRN. 1999. Coral suspension feeding on fine particulate matter, Journal of Experimental Marine Biology and Ecology 232:85-106.

Anthony KRN, Hoogenboom MO, Maynard JA, Grottoli AG, Middlebrook R. 2009. Energetics approach to predicting mortality risk from environmental stress: a case study of coral bleaching. Functional Ecology 23:539-550.

Buckel JA, Stoner AW. 2000. Functional response and switching behavior of young-of-the-year piscivorous bluefish. Journal of Experimental Marine Biology and Ecology 245: 25-41.

Cairns SD. 1982. Antarctic and Subantarctic Scleractinia. Antarctic Research Series 34: 74.

Cairns SD. 1995. The marine fauna of New Zealand: Scleractinia (Cnidaria, Anthozoa). New Zealand Oceanographic Institute Memoir 103:210.

Cairns SD, Stanley GDJ. 1982. Ahermatypic coral banks: living and fossil counterparts. In: Gomez ED, Birkeland CE, et al. eds., Proceedings of the 4th international coral reef symposium marine sciences center. Manila: University of the Philippines, 1:611-618.

Cairns SD, Försterra G, Häussermann V. 2005. A review of the Scleractinia (Cnidaria, Anthozoa) of Chile, with the description of two new species. Zootaxa 118:15-46.

Carlier A, Le Guilloux E, Olu K. Sarrazin J, Mastrototaro F, Taviani M, Clavier J. 2009. Trophic relationships in a deep Mediterranean cold-water coral bank (Santa Maria di Leuca, Ionian Sea). Marine Ecology Progress Series 397:125-137.

Doney SC, Fabry VJ, Feely RA, Kleypas A. 2009. Ocean acidification: the other $\mathrm{CO}_{2}$ problem. Annual Review Marine Science 1:169-192.

Duineveld GCA, Lavaleye MSS, Berghuis EM. 2004. Particle flux and food supply to a seamount cold-water coral community (Galicia Bank, NW Spain). Marine Ecology Progress Series 277:13-23. 
Fillinger L, Richter C. 2013. Vertical and horizontal distribution of Desmophyllum dianthus in Comau Fjord, Chile: a cold-water coral thriving at low pH. PeerJ 1:e194 DOI 10.7717/peerj.194.

Findlay HS, Hennige SJ, Wicks LC, Navas JM, Woodward EMS, Roberts JM. 2014. Finescale nutrient and carbonate system dynamics around cold-water coral reefs in the northeast Atlantic. Scientific Reports 4:3671 DOI:10.1038/srep03671

Folt CL, Burns CW. 1999. Biological drivers of zooplankton patchiness. Trends in Ecology and Evolution 14: 300 - 305. https://doi.org/10.1016/S0169-5347(99)01616-X

Försterra G, Beuck L, Häussermann V, Freiwald A. 2005. Shallow-water Desmophyllum dianthus (Scleractinia) from Chile: characteristics of the biocoenoses, the bioeroding community, heterotrophic interactions and (paleo)-bathymetric implications. In: Freiwald A, Roberts JM (eds) Cold-water corals and ecosystems, Springer-Verlag Berlin:937-977.

Försterra G, Häussermann V. 2003. First report on large scleractinian (Cnidaria: Anthozoa) accumulations in cold-temperate shallow water of south Chilean fjords. Zoologische Verhandlungen Leiden 345:117-128.

Freiwald A, Fossa JH, Grehan A, Koslow T, Roberts JM. 2004. Cold-water coral reefs, out of sight-no longer out of mind. UNEP-WCMC, Cambridge.

Genin A, Jaffe JS, Reef R, Richter C, Franks PJS. 2005. Swimming against the flow: the mechanism of zooplankton aggregation. Science 308:860-862.

González HE, Daneri G, Iriarte JL, Yannicelli B, Menschel E, Barría C, Pantoja S, Lizárraga L. 2009. Carbon fluxes within the epipelagic zone of the Humboldt current System off Chile: the significance of euphausiids and diatoms as key functional groups for the biological pump. Progress in Oceanography 83:217-227.

González HE, Calderón MJ, Castro L, Clement A, Cuevas LA, Daneri G, Iriarte JL, Lizárraga L, Martínez R, Menschel E, Silva N, Carrasco C, Valenzuela C, Vargas CA, Moline C. 2010. Primary production and plankton dynamics in the Reloncaví Fjord and the interior Sea of Chiloé, Northern Patagonia, Chile. Marine Ecology Progress Series 402:13-30.

González HE, Castro L, Daneri G, Iriarte JL, Silva N, Vargas CA, Giesecke R, Sánchez N. 2011. Seasonal plankton variability in Chilean Patagonia fjords: Carbon flow through the pelagic food web of Aysen Fjord and plankton dynamics in the Moraleda Channel basin. Continental Shelf Research 31:225-243.

González HE, Graeve M, Kattner G, Silva N, Castro L, Iriarte JL, Osmán L, Daneri G, Vargas CA. 2016. Carbon flow through the pelagic food web in southern Chilean 
409

410

411

412

413

414

415

416

417

418

419

420

421

422

423

424

425

426

427

428

429

Patagonia: Relevance of Euphausia vallentini as a key species. Marine Ecology Progress Series 557:91-110.

Gori A, Ferrier-Pagès C, Hennige SJ, Murray F, Rottier C, Wicks LC \& Roberts JM. 2016. Physiological response of the cold-water coral Desmophyllum dianthus to thermal stress and ocean acidification. PeerJ 4:e1606; DOI 10.7717/peerj.1606

Green S, Visser AW, Titelman J, Kiørboe T. 2003. Escape response of copepod nauplii in the flow field of the blue mussel, Mytilus edulis. Marine Biology 142:727-733.

Guinotte JM, Orr J, Cairns S, Freiwald A, Morgan L, George R. 2006. Will human-induced changes in seawater chemistry alter the distribution of deep-sea scleractinian corals? Frontiers in Ecology and the Environment 4:141-146.

Haddaway NR, Wilcox RH, Heptonstall REA, Griffiths HM, Mortimer RJG, Christmas M, Dunn AM. 2012. Predatory functional response and prey choice identify predation. Differences between native/invasive and parasitised/unparasitised crayfish. PLOS ONE 7: e32229. doi:10.1371/journal.pone.0032229

Hamame M, Antezana T. 2010. Vertical migration and feeding of Euphausia vallentini within southern Chilean fjords. Deep-Sea Research II 57:642-651.

Haury LR, Kenyon DE, Brooks JR. 1980. Experimental evaluation of the avoidance reaction of Calanus finmarchicus. Journal of Plankton Research 2:187-202.

Heindel K, Titschack J, Dorschel B, AI Huvenne V, Freiwald A. 2010. The sediment composition and predictive mapping of facies on the Propeller Mound-A cold-water coral mound (Porcupine Seabight, NE Atlantic). Continental Shelf Research 30:18141829.

Hirche HJ, Laudien J, Buchholz F. 2016. Near-bottom zooplankton aggregations in Kongsfjorden: implications for pelago-benthic coupling. Polar Biology 39:1897-1912.

Holling CS. 1959. The components of predation as revealed by a study of small-mammal predation of the European pine sawfly. Canadian Entomology 91:293-320.

Holling, CS. 1965. The Functional response of predators to prey density and its role in mimicry and population regulation. Memoir of the Entomological Society of Canada 97:1-60. doi: $10.4039 /$ entm9745fv

Holling CS. 1966. The functional response of invertebrate predators to prey density. Memoirs of the Entomological Society of Canada 98:5-86. 
430

431

432

433

434

435

436

437

438

439

440

441

442

443

444

445

446

447

448

449

450

451

452

453

454

455

456

457

458

459

460

461

462

463

Jantzen C, Häussermann V,Försterra G, Laudien J, Ardelan M, Maier S, Richter C. $2013 a$. Occurrence of a cold-water coral along natural $\mathrm{pH}$ gradients (Patagonia, Chile). Marine Biology 160:2597-2607.

Jantzen C, Laudien J, Sokol S, Försterra, G, Häussermann V, Kupprat F, Richter C. 2013b. In situ short-term growth rates of a cold-water coral. Marine Freshwater Research 64:631-641.

Jeschke J, Kopp M, Tollrian R. 2004. Consumer-food systems: Why type I functional responses are exclusive to filter feeders. Biological Reviews 79:337-349.

Juliano SA. 2001. Nonlinear curve fitting: predation and functional response curves. In: Scheiner SM, Gurevitch J (eds) Design and analysis of ecological experiments. Oxford University Press, Oxford, 178-196

Kerfoot WC. 1978. Combat between predatory copepods and their prey: Cyclops, Epischura and Bosmina. Limnology and Oceanography 23:1089- 1102.

Kiørboe T, Saiz E, Visser A. 1999. Hydrodynamic signal perception in the copepod Acartia tonsa. Marine Ecology Progress Series 179:97-111.

Kiriakoulakis K, Fisher L, Freiwald A, Grehan A, Roberts M, Wolff GA. 2005. Lipids and nitrogen isotopes of two deep-water corals from the North-East Atlantic: initial results and implications for their nutrition. In: Freiwald A, Roberts JM (eds) Cold-water corals and ecosystems, Springer-Verlag Berlin:159-170.

Lasker HR. 1981. A comparison of the particulate feeding abilities of three species of gorgonian soft coral. Marine Ecology Progress Series 5:61-67.

Lebrato M, Andersson AJ, Ries JB, Aronson RB, Lamare MD, Koeve W, Ooschiles A, Iglesias-Rodríguez MD, Thatje S, Amsler M, Vos SC, Jones DOB, Ruhl HA, Gates AR, Mcclintock JB. 2016. Benthic marine calcifiers coexist with $\mathrm{CaCO} 3$-undersaturated seawater worldwide. Global Biogeochemical Cycles, 10.1002/2015GB005260.

Maier C, Watremez P, Taviani M, Weinbauer MG, Gattuso J-P. 2012. Calcification rates and the effect of ocean acidification on Mediterranean coldwater corals. Proceedings of the Royal Society of. London B 279:1713-1723 doi: 10.1098/rspb.2011.1763.

Maier C, Schubert A, Sánchez MMB, Weinbauer MG, Watremez P, Gattuso JP. 2013. End of the century pCO2 levels do not impact calcification in Mediterranean cold-water corals. PLoS ONE 8:e62655 DOI 10.1371/journal.pone.0062655

Mayr CC, Försterra G, Häussermann V, Wunderlich A, Grau J, Zieringer M, Altenbach AV. 2011. Stable isotope variability in a Chilean fjord food web: implications for N- and C-cycles. Marine Ecology Progress Series 428:89-104. 
464

465

466

467

468

469

470

471

472

473

474

475

476

477

478

479

480

481

482

483

484

485

486

487

488

489

490

491

492

493

494

495

496

McCulloch M, Falter J, Trotter J, Montagna P. 2012b. Coral resilience to ocean acidification and global warming through $\mathrm{pH}$ up-regulation. Nature Climate Change Letter 2:623-627.

McCulloch M, Trotter J, Montagna P, Falter J, Dunbar R, Freiwald A, Försterra G, López Correa M, Maier C, Rüggeberg A, Taviani M. 2012a. Resilience of cold-water scleractinian corals to ocean acidification: boron isotopic systematics of $\mathrm{pH}$ and saturation state up-regulation. Geochimica Cosmochimica Acta 87:21-34.

Murdoch WW. 1977. Stabilizing effects of spatial heterogeneity in predator-prey systems. Theoretical Population Biology 11:252-273 doi:10.1016/0040-5809(77)90028-4

Naumann MS, Orejas C, Wild C, Ferrier-Pagès C. 2011. First evidence for zooplankton feeding sustaining key physiological processes in a scleractinian cold-water coral. Journal of Experimental Biology 214:3570-3576.

Orejas C, Gili JM, López-González PJ, Arntz W. 2001. Feeding strategies and diet composition of four Antarctic cnidarian species. Polar Biology 24:620-627.

Orejas C, Gili JM, Arntz W. 2003. The role of the small-plankton communities in the diet of two Antarctic octocorals (Primnoisis antarctica and Primnoella sp.). Marine Ecology Progress Series 250:105-116.

R Core Team. 2012. $R$ : a language and environment for statistical computing. Vienna: $\mathrm{R}$ Foundation for Statistical Computing. Available at http://www.R-project.org

Reveillaud J, Freiwald A, Van Rooij D, Le Guilloux E, Altuna A, Foubert A,Vanreusel A, Roy KO, Henriet JP. 2008. The distribution of scleractinian corals in the Bay of Biscay, NE Atlantic. Facies 54:317-331.

Ribes M, Coma R, Rossi S. 2003. Natural feeding of the temperate asymbiotic octocoralgorgonian Leptogorgia sarmentosa. Marine Ecology Progress Series 254:141-150.

Roberts MJ, Wheeler AJ, Freiwald A, Cairns S. 2009. Cold-water corals. The biology and geology of deep-sea coral habitats. Cambridge, Cambridge University Press.

Sánchez N, González HE, Iriarte JL. 2011. Trophic interactions of pelagic crustaceans in Comau Fjord (Chile): their role in food web structure. Journal of Plankton Research 33:1212-1229.

Schwabe E, Försterra G, Häussermann V, Melzer R, Schrödl M. 2006. Chitons (Mollusca: Polyplacophora) from the southern Chilean Comau Fjord, with reinstatement of Tonicia calbucensis Plate, 1897. Zootaxa 1341:1-27.

Squires DF. 1965. Deep-water coral structure on the Campbell Plateau, New Zealand. Deep-Sea Research and Oceanographic abstracts 12:785-788. 
497

498

499

500

501

502

503

504

505

506

507

508

509

510

511

512

513

514

515

Strickler JR \& Bal AK. 1973. Setae of the first antennae of the copepod Cyclops scutifer (Sars): their structure and importance. Proceedings of the National Academy of Sciences USA 70:2656-2659.

Titelman J, Kiørboe T. 2003. Predator avoidance by nauplii. Marine Ecology Progress Series 247:137-149.

Tsounis G, Rossi S, Laudien J, Bramanti L, Fernández N, Gili JM, Arntz W. 2006. Diet and seasonal prey capture rates in the Mediterranean red coral (Corallium rubrum L.). Marine Biology 149:313-325.

Tsounis G, Orejas C, Stéphanie Reynaud S, Gili JM, Allemand D, Ferrier-Pagès C. 2010. Prey-capture rates in four Mediterranean cold water corals. Marine Ecology Progress Series 398:149-155.

Trexler JC, McCulloch CE, Travis J. 1988. How can the functional response best be determined? Oecologia 76:206-214.

Viitasalo M, Kiørboe T, Flinkman J, Pedersen LW, Visser AW. 1998. Predation vulnerability of planktonic copepods: consequences of predator foraging strategies and prey sensory abilities. Marine Ecology Progress Series 175:129-142.

Yen J, Lenz PH, Gassie DV, Hartline DK. 1992. Mechanoreception in marine copepods: electrophysiological studies on the first antennae. Journal of Plankton Research 14:459512. 


\section{Figure 1}

Coral in the laboratory at the end of an incubation.

(A) Specimen of Desmophyllum dianthus inside an incubation bottle. (B) Fully extended tentacles of the same coral in detail. Photos by N. García-Herrera.

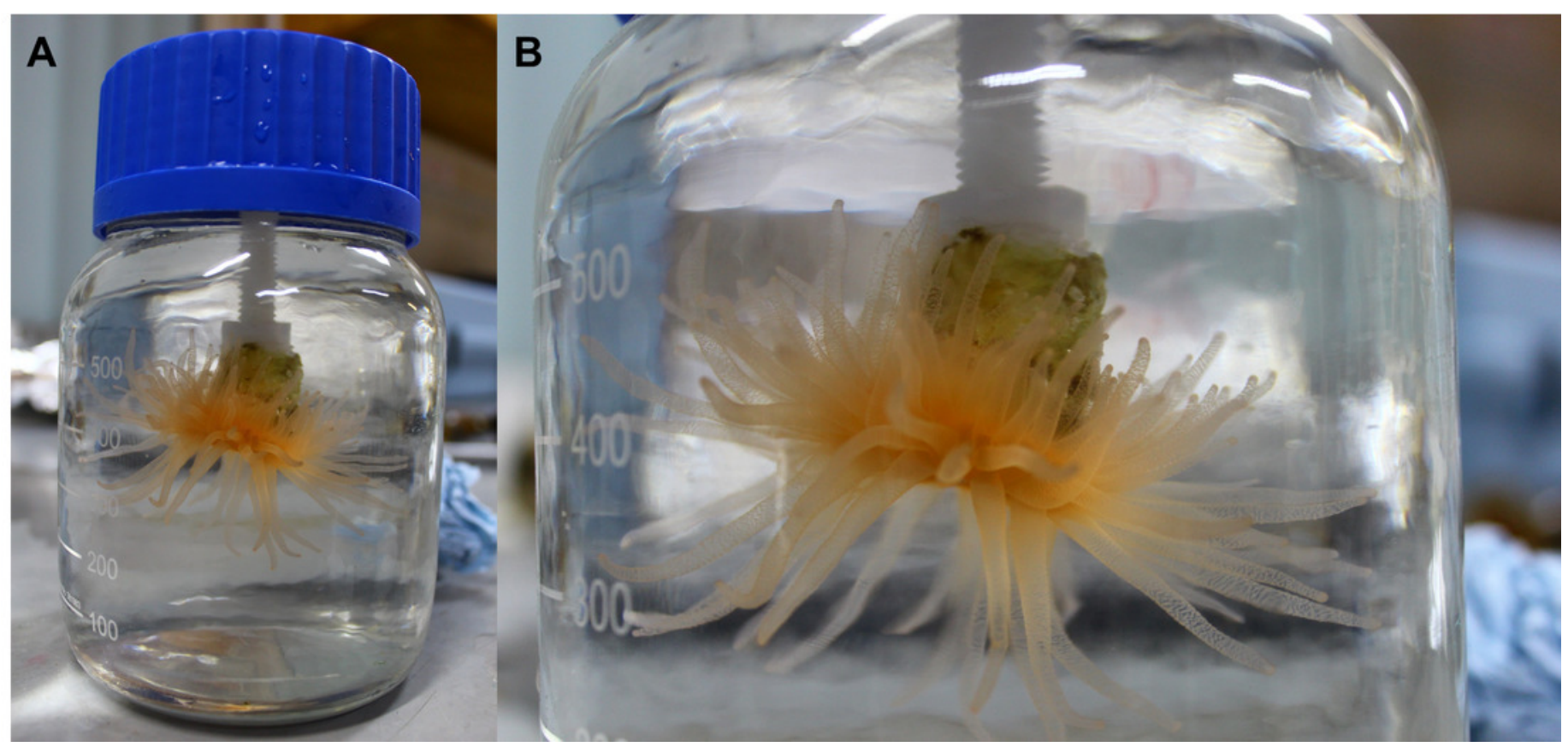


Figure 2

Scatter plot showing the prey abundance (number of prey $\mathrm{L}^{-1}$ ) and the proportion of prey (parts per unit) ingested by corals $\left(\% / \mathrm{h}^{-1}\right)$.

(A) Data for Calanoides patagoniensis incubations. (B) Data for Euphausia vallentini incubations. Solid black lines represent the mean proportion of prey ingested by feeding corals, while dashed grey lines correspond to the non-significant second-order logistic regression fits.

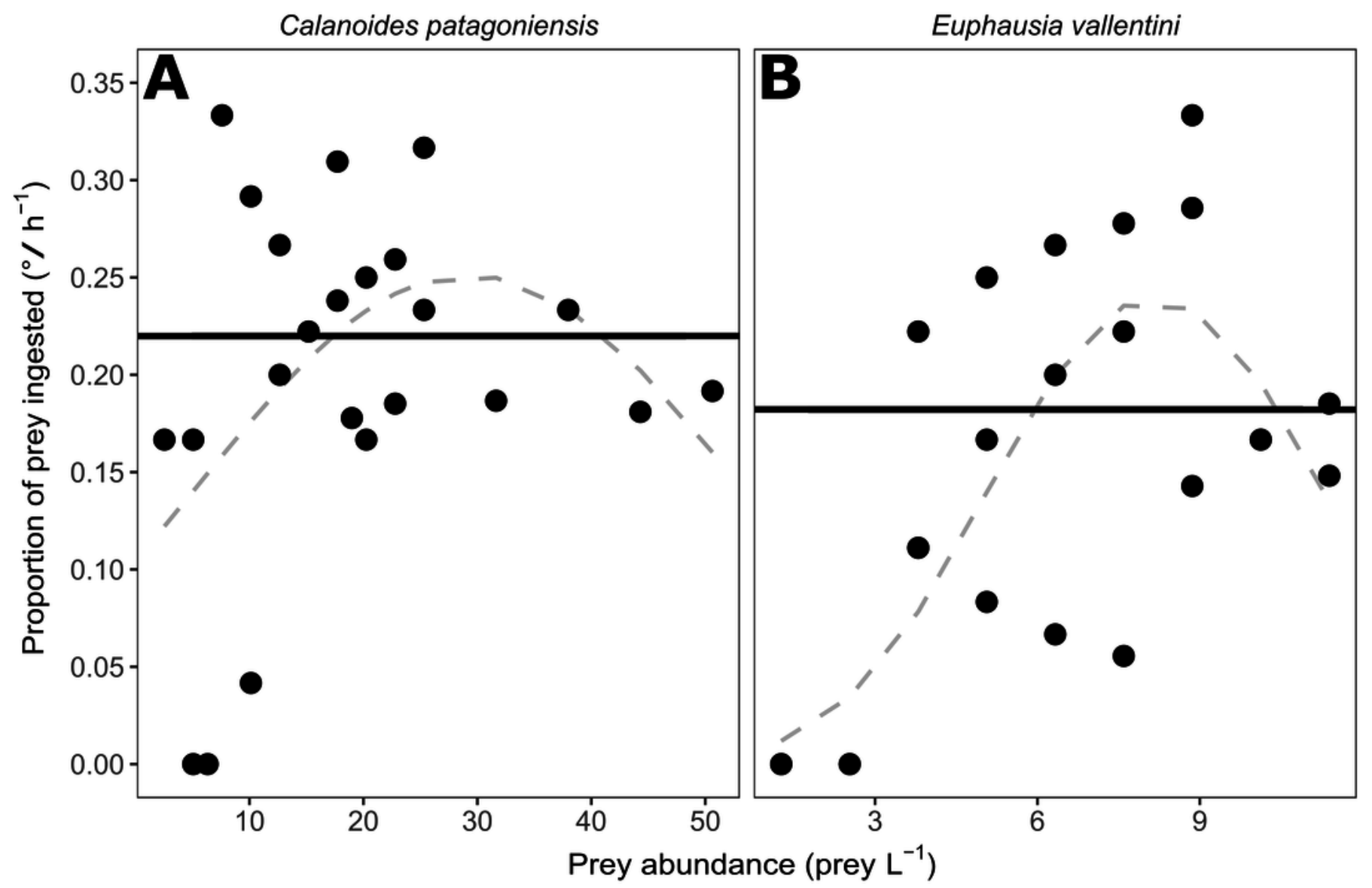


Figure 3

Scatter plot showing the relationship between prey abundance (prey $\left.\mathrm{L}^{-1}\right)$ and coral ingestion rate $\left(\mathrm{mg} \mathrm{Ch}^{-1}\right)$.

(A) Data for Calanoides patagoniensis. (B) Data for Euphausia vallentini. Solid lines represent linear fits, whereas dashed lines correspond to their $95 \%$ confidence intervals.
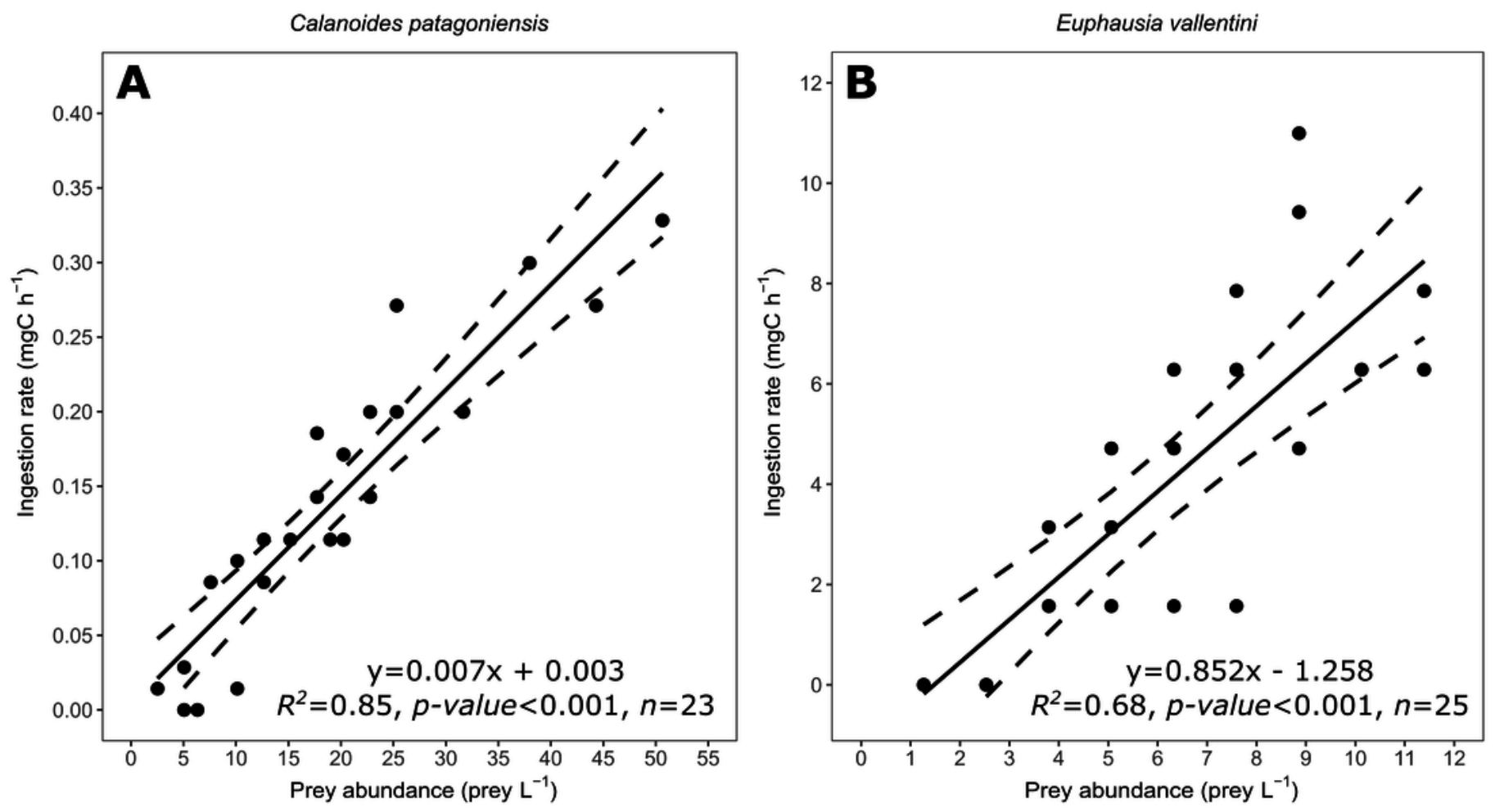
Figure 4

Scatter plot showing the relationships between prey biomass $\left(\mathrm{mg} \mathrm{C} \mathrm{L}^{-1}\right)$ and coral daily ration (\% of coral carbon biomass $\mathrm{d}^{-1}$ ).

(A) Data for Calanoides patagoniensis. (B) Data for Euphausia vallentini. Black solid lines represent linear fits, whereas black dashed lines correspond to their $95 \%$ confidence intervals. Grey dashed lines correspond to a linear regression with a slope of 4.85 .
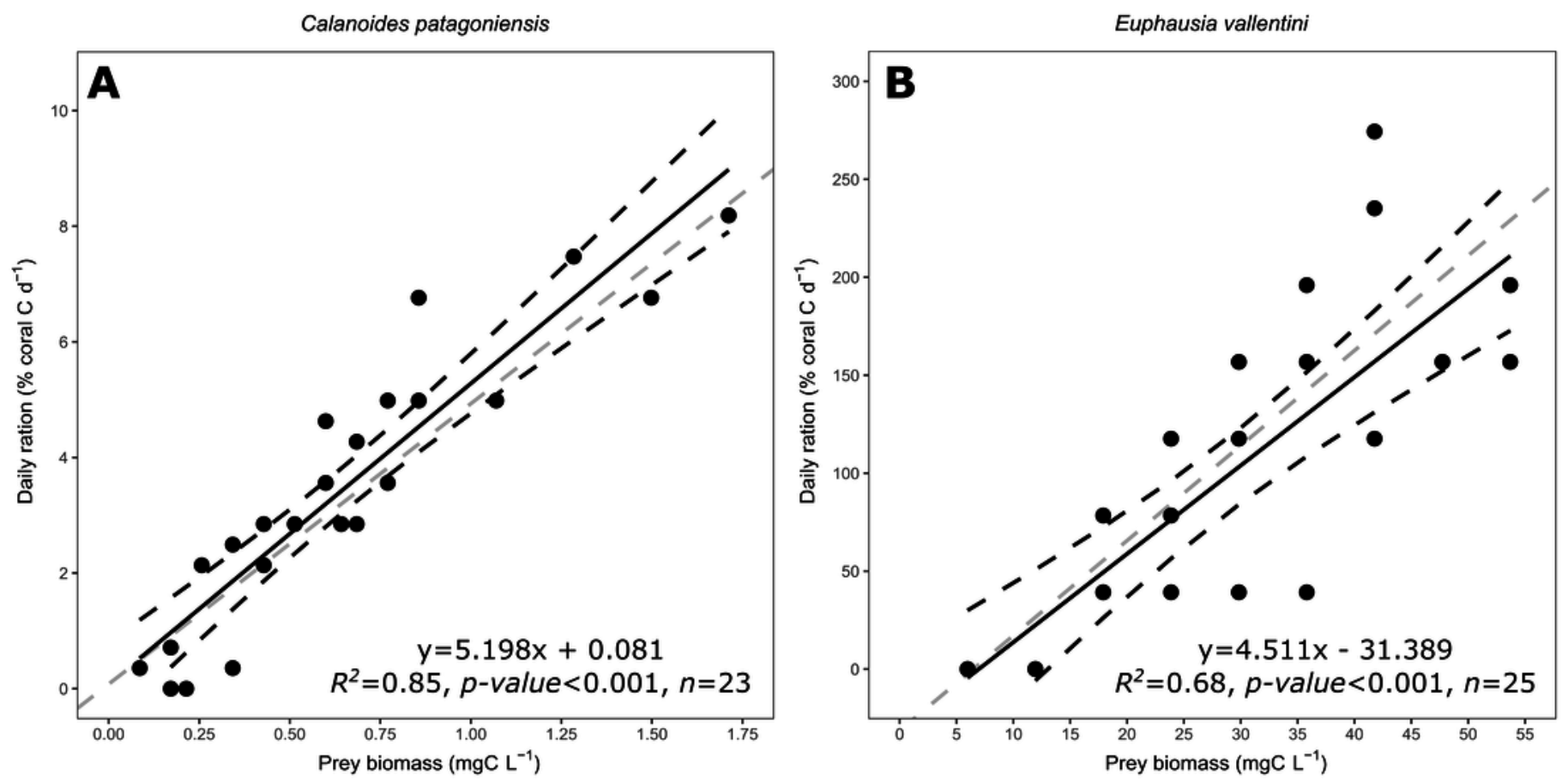


\section{Table $\mathbf{1}$ (on next page)}

Details of incubations used to assess the functional response of Desmophyllum dianthus.

Date of the incubation, prey type, minimum prey abundance (Min PA, prey $\mathrm{L}^{-1}$ ), maximum prey abundance (Max PA, prey $\mathrm{L}^{-1}$ ), number of corals used $(N)$, incubation starting time (Start time), incubation ending time (End time) and mean \% of oxygen consumed during incubations (Oxy con). CP and EV stands for Calanoides patagoniensis and Euphausia vallentini, respectively. Below are the mean carbon biomass of the corals and prey used during the incubations and the standard errors (SE) associated with these means. 


\begin{tabular}{cccccccc} 
Date & Prey type & Min PA Max PA & N & Start time & End time & Oxy con \\
\hline $11 / 09 / 2016$ & EV & 1.26 & 11.39 & 9 & $00: 30$ & $03: 30$ & 8.8 \\
$13 / 09 / 2016^{\text {(a) }}$ & CP & 2.53 & 22.78 & 6 & $23: 30$ & $02: 30$ & 1.7 \\
$15 / 12 / 2016$ & EV & 1.26 & 10.12 & 8 & $01: 00$ & $04: 00$ & 5.4 \\
$17 / 12 / 2016$ & CP & 5.06 & 25.31 & 9 & $23: 00$ & $02: 00$ & 2.2 \\
$06 / 05 / 2017^{\text {(b) }}$ & EV & 1.26 & 11.39 & 8 & $23: 30$ & $02: 30$ & 3.2 \\
$14 / 05 / 2017^{\text {(c) }}$ & CP & 6.33 & 50.63 & 8 & $23: 30$ & $02: 30$ & 4.1 \\
global $_{\text {global }}$ & EV & 1.26 & 11.39 & 25 & & & 5.8 \\
\hline
\end{tabular}

\begin{tabular}{ccc} 
Organism & Mean carbon biomass (mg C) & SE \\
\hline Desmphyllum dianthus & 96.198 & 8.5000 \\
Euphausia vallentini & 4.713 & 0.3300 \\
Calanoides patagonensis & 0.043 & 0.0063 \\
\hline
\end{tabular}

${ }^{a}$ During this incubation two bottles were discarded before starting the functional response experiment due to unhealthy (i.e. non-swimming) copepods

${ }^{b, c}$ The corals used for these incubations were collected on different days 


\section{Table 2 (on next page)}

Functional response type.

Terms and their $p$-value (inside brackets) for the second-order logistic regression used to analyze the relationship between prey abundance and the proportion of prey ingested by corals (i.e. analysis to determine functional response type). 


\begin{tabular}{cccc} 
& Prey & First-order term & Second-order term \\
\cline { 2 - 4 } & Calanoides patagoniensis & $0.63(0.81)$ & $-1.08(0.68)$ \\
1 & Euphausia vallentini & $4.38(0.34)$ & $-3.11(0.43)$ \\
\cline { 2 - 4 }
\end{tabular}




\section{Table 3 (on next page)}

Model selection for the linear and logarithmic models fitted to coral ingestion rate and prey abundance for Calanoides patagoniensis and Euphausia vallentini.

The best fitting model according to second order Akaike Information Criterion (AICC) is highlighted in bold. The table also shows the difference in AICc between both models (Delta AICC), the relative weight of each model (AICC Wt), the cumulative weight of the models (Cum Wt), the proportion of the variance explained by each model $\left(R^{2}\right)$ and model significance ( $p$-value). 


\begin{tabular}{|c|c|c|c|c|c|c|c|}
\hline Prey & Fit & $\mathrm{AlCC}$ & Delta AICc & $\mathrm{AlCc} W \mathrm{t}$ & Cum Wt & $R^{2}$ & $p$-value \\
\hline Calanoides patagoniensis & Linear & 237.42 & 0.00 & 0.93 & 0.93 & 0.85 & $<0.001$ \\
\hline Calanoides patagoniensis & Logarithmic & 242.74 & 5.33 & 0.07 & 1.00 & 0.81 & $<0.001$ \\
\hline Euphausia vallentini & Linear & 108.37 & 0.00 & 0.79 & 0.79 & 0.68 & $<0.001$ \\
\hline Euphausia vallentini & Logarithmic & 111.08 & 2.71 & 0.21 & 1.00 & 0.64 & $<0.001$ \\
\hline
\end{tabular}

